\title{
Dissociable effects of mGluR5 allosteric modulation on distinct forms of impulsivity in rats: interaction with NMDA receptor antagonism
}

\author{
Sarah N. Isherwood ${ }^{1,2}$, Anton Pekcec ${ }^{1 \#}$, Janet R. Nicholson ${ }^{1}$, Trevor W. Robbins ${ }^{2}$, \\ Jeffrey W. Dalley ${ }^{2,3}$
}

${ }^{1}$ Boehringer Ingelheim Pharma GmbH \& Co. KG, Div. Research Germany, Birkendorfer Strasse 65, 88397, Biberach an der Riss, Germany; ${ }^{2}$ Department of Psychology and Behavioural and Clinical Neuroscience Institute, University of Cambridge, Downing Street, Cambridge, CB2 3EB; ${ }^{3}$ Department of Psychiatry, University of Cambridge, Downing Street, Cambridge, CB2 2QQ

\section{\#Corresponding Author:}

Anton Pekcec, Boehringer Ingelheim Pharma GmbH \& Co. KG, Div. Research Germany, Birkendorfer Strasse 65, 88397, Biberach an der Riss, Germany. Tel.: +49-73515492312; Fax: 49-73518392312; Email: anton.pekcec@boehringer-ingelheim.com

Supp1ementary 1: Effect of increasing doses of MK801 on 5-CSRTT performance - cohort 1 Results

The effects of MK801 on 5-CSRTT performance, 10 minutes after administration, are shown in Fig. S1. MK801 significantly increased \% premature responding $\left(F_{2,22}=4.0, p<0.05, X^{2}=30\right.$, GG $\varepsilon=0.50)$ compared with vehicle-treated rats. This effect was significant at $0.06 \mathrm{mg} / \mathrm{kg}$ $(\mathrm{p}<0.05)$, increasing \% premature responding from $6.08 \pm 1.3$ to $50.1 \pm 14.7 \%$. However, the individual response to MK801 was highly variable; the range of premature responses elicited by $0.06 \mathrm{mg} / \mathrm{kg}$ varied between 3 and $140 \%$.

Although there was an overall increase in omissions (main effect of dose, $F_{1,14}=52.5$, $p<0.001$, $\mathrm{X}^{2}=50$, GG $\varepsilon=0.32$ ) and decrease in accuracy (main effect of dose, $F_{2.20}=8.4, p<0.01, X^{2}=29$, GG $\varepsilon=0.45$ ), these effects were only evident following $0.1 \mathrm{mg} / \mathrm{kg}$ MK801 administration 
( $\mathrm{p}<0.001$ and $\mathrm{p}<0.05$ respectively). Indeed, $0.06 \mathrm{mg} / \mathrm{kg} \mathrm{MK} 801 \mathrm{had}$ no effect on any other behavioural variable apart from magazine latencies $\left(F_{1,15}=6.6, p<0.05, X^{2}=39\right.$, GG $\left.\varepsilon=0.37\right)$ where MK801 produced a significant dose-dependent decrease in the latency to collect food reward at $0.015,0.03$ and $0.06 \mathrm{mg} / \mathrm{kg}(\mathrm{p}<0.001)$ (data not shown).

Based on these results, a dose of $0.06 \mathrm{mg} / \mathrm{kg}$ MK801 was selected for MK801 studies in cohort 1 . This dose provided a selective increase in premature responding, without having any substantial effect on other behavioural variables.

Fig. S1

(a)

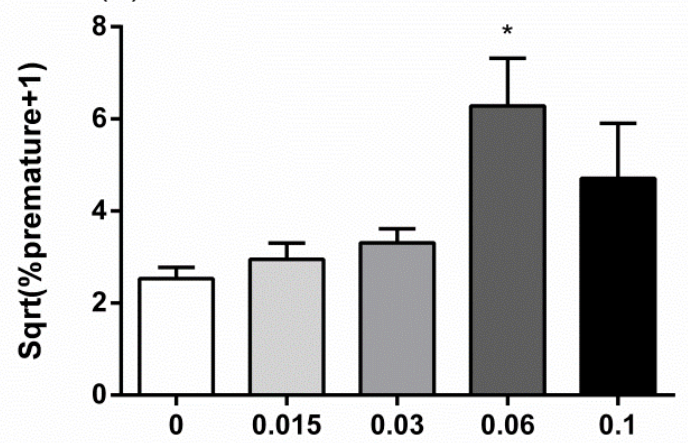

(c)

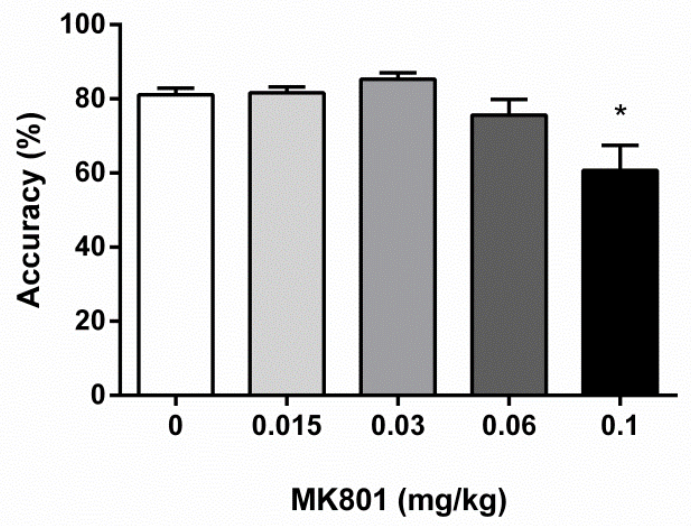

(b)

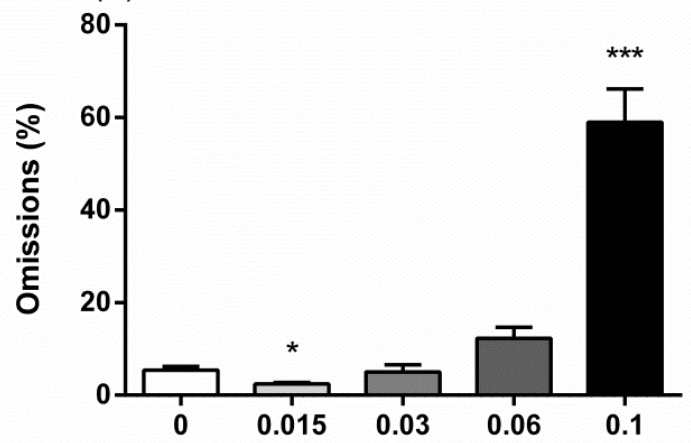

(d)

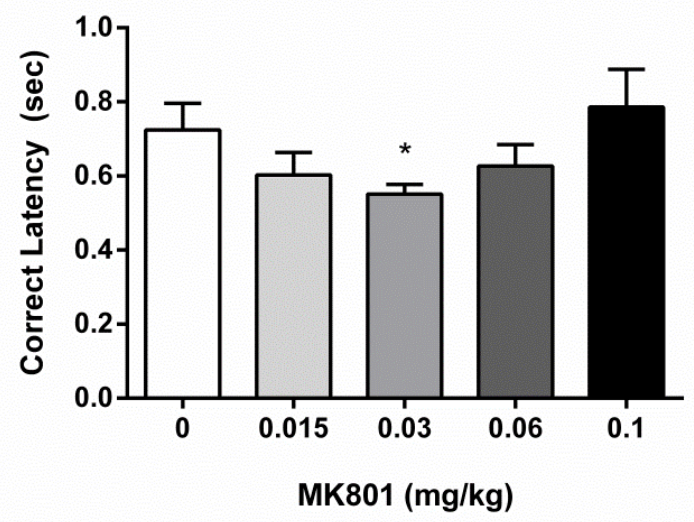

Fig. S1: Dose-dependent effects of MK801 (0-0.1 mg/kg) on 5-CSRTT performance $(\mathrm{n}=12)$; (a) \% premature responses, (b) \% omissions, (c) \% accuracy, (d) correct response latency (sec). Bars represent means \pm SEM. Repeated measures one-way ANOVA, Dunnett's post hoc test $* \mathrm{p}<0.05, * * * \mathrm{p}<0.001$ versus vehicle control. Premature responding data were transformed (SQRT (\% premature +1$)$ to satisfy the requirement of homogeneity of variance. 
Supplementary 2: Effect of increasing doses of MK801 on 5-CSRTT performance - cohort 2 Results

The effects of MK801 on 5-CSRTT performance, 10 minutes after administration, are shown in Fig. S2. MK801 significantly and dose-dependently increased premature responding $\left(\mathrm{F}_{2,27}=4.7, \mathrm{p}<0.05\right)$, reaching significance at $0.06 \mathrm{mg} / \mathrm{kg}$ only $(\mathrm{p}<0.01)$. No other task parameter was affected by MK801 at any dose apart from a significant increase in speed to respond correctly $\left(\mathrm{F}_{2,27}=3.4, \mathrm{p}<0.05\right)$, following $0.03 \mathrm{mg} / \mathrm{kg} \mathrm{MK801}(\mathrm{p}<0.05)$.

Based on these data, a dose of $0.03 \mathrm{mg} / \mathrm{kg}$ was selected for MK801 studies in cohort 2 . Although non-significant, a robust, selective increase in premature responding was observed following $0.03 \mathrm{mg} / \mathrm{kg}$ MK801. Furthermore, it was apparent that the effect of $0.06 \mathrm{mg} / \mathrm{kg}$ MK801 on premature responding was large and variable between different subjects. 
Fig. S2

(a)

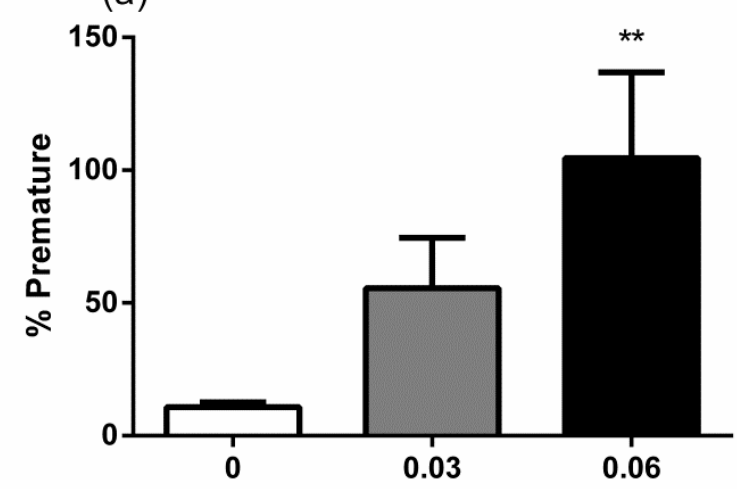

(c)

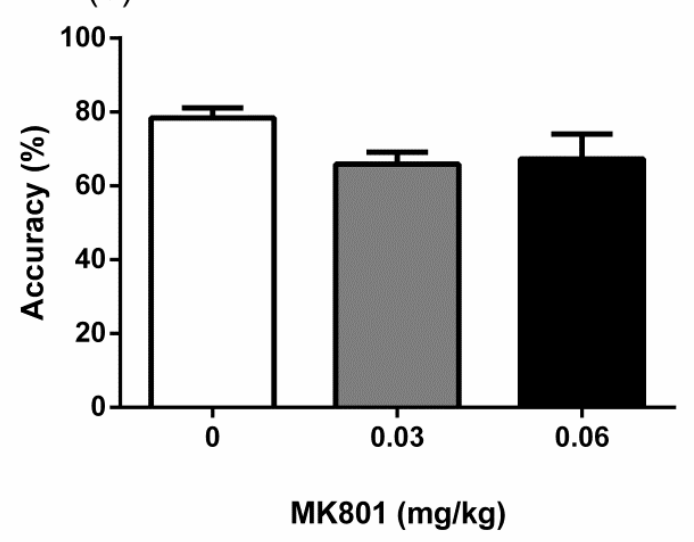

(b)

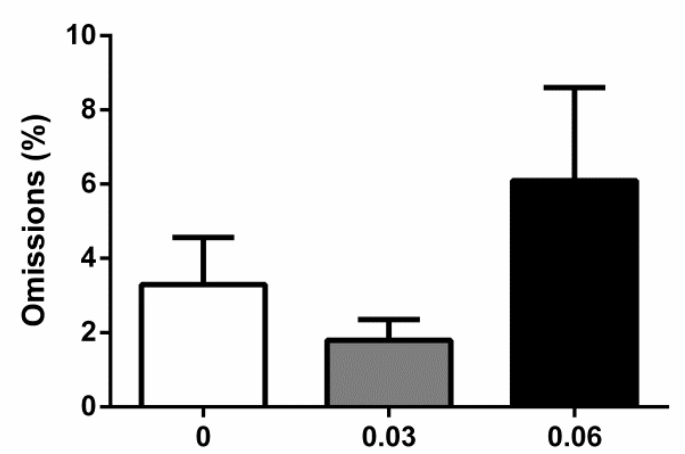

(d)

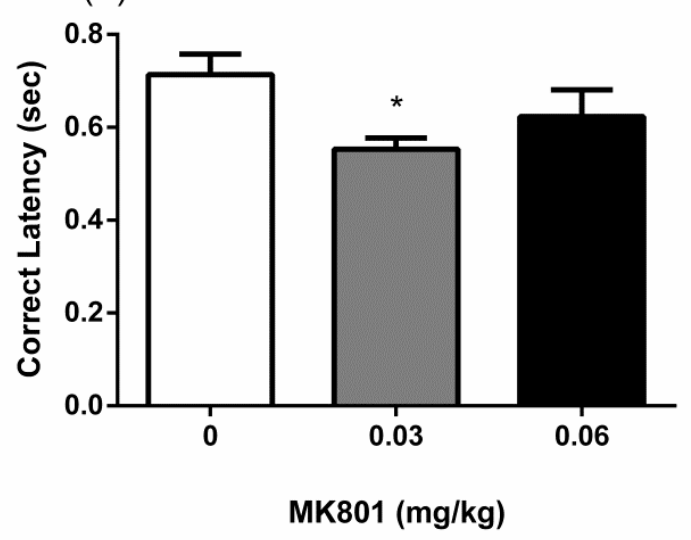

Fig. S2: Dose-dependent effects of MK801 (0-0.06 mg/kg) on 5-CSRTT performance ( $\mathrm{n}=30)$; (a) \% premature responses, (b) \% omissions, (c) \% accuracy, (d) correct response latency (sec). Bars represent means \pm SEM. One-way ANOVA, Dunnett's post hoc test. * $\mathrm{p}<0.05, * *$ $\mathrm{p}<0.01$ versus vehicle control. 
Supplementary 3: Pharmacokinetic properties of RO4917523 and ADX47273

\section{Table S1}

\begin{tabular}{|l|l|}
\hline RO4917523 & \\
Molecular weight: 325.8 & \\
Dose: $17.9 \mu \mathrm{M} / \mathrm{kg}(5.8 \mathrm{mg} / \mathrm{kg})$, p.o & Mean $(\mathrm{n}=3)$ \\
\hline Cmax [nM] & 3740 \\
\hline Tmax [h] & 2.0 \\
\hline MRT [h] & 7 \\
\hline ADX47273 & \\
Molecular weight: 369.4 & \\
Dose: $271 \mu M / \mathrm{kg}(100 \mathrm{mg} / \mathrm{kg})$ p.o & Mean $(\mathrm{n}=3)$ \\
\hline Cmax [nM] & 5510 \\
\hline Tmax [h] & 1.33 \\
\hline MRT [h] & 6.6 \\
\hline
\end{tabular}

Table S1: Pharmacokinetic properties of RO4917523 and ADX47273 in male Wistar rats, following oral administration of $5.8 \mathrm{mg} / \mathrm{kg} \mathrm{RO} 4917523$ or $100 \mathrm{mg} / \mathrm{kg}$ ADX47273; maximal plasma concentration (Cmax), time taken to reach maximal plasma concentration (Tmax) and mean residence time (MRT) indicated ( $\mathrm{n}=3$ per group). 
Supplementary 4: Plasma exposures of RO4917523, MTEP and ADX47273

\section{Table S2}

\begin{tabular}{|c|c|}
\hline $\begin{array}{c}\text { RO4917523 } \\
\text { (mg/kg), p.o; } \\
2 \text { hrs 15 mins } \\
\mathrm{n}=3 \text { per group }\end{array}$ & $\begin{array}{c}\text { Mean Plasma } \\
\text { Concentration } \\
(\mathrm{nM})\end{array}$ \\
\hline 0.03 & $\mathrm{n} / \mathrm{a}^{*}$ \\
\hline 0.1 & $25 \pm 0^{* *}$ \\
\hline 0.3 & $71.2 \pm 25.5$ \\
\hline 1 & $152.7 \pm 7.8$ \\
\hline MTEP \\
$\begin{array}{c}\text { (mg/kg), i.p; } \\
30 \text { mins; } \\
\mathrm{n}=3 \text { per group }\end{array}$ & $\begin{array}{c}\text { Mean Plasma } \\
\text { Concentration } \\
\text { (nM) }\end{array}$ \\
\hline 1 & $411.7 \pm 104.7$ \\
\hline 3 & $2063.3 \pm 266.7$ \\
\hline 10 & $11158.7 \pm 3978.5$ \\
\hline 30 & $28015.3 \pm 8568.0$ \\
\hline $\begin{array}{c}\text { ADX47273 } \\
(\mathrm{mg} / \mathrm{kg}), \text { p.o; } \\
1 \mathrm{hr} 45 \text { mins; } \\
\mathrm{n}=4 \text { per group }\end{array}$ & $\begin{array}{c}\text { Mean Plasma } \\
\text { Concentration } \\
\text { (nM) }\end{array}$ \\
\hline 80 & $2235.0 \pm 210.0$ \\
\hline 100 & $2550.0 \pm 326.4$ \\
\hline
\end{tabular}

* Below detectable range; $* * n=1$ (two samples below detectable range)

Table S2: Mean plasma concentrations of RO4917523 $(0.03-1 \mathrm{mg} / \mathrm{kg}$, p.o, at 2 hours 15 minutes), MTEP (1 - $30 \mathrm{mg} / \mathrm{kg}$, i.p, at 30 minutes) and ADX47273 (80 - $100 \mathrm{mg} / \mathrm{kg}$, p.o, at 1 hr 45 minutes) post administration, in male Lister hooded rats. Time points based on plasma exposures mid-task (i.e. 15 minutes into task). 


\section{Supplementary 5: In-vitro characterisation of allosteric mGluR5 modulation}

\section{Material and methods}

Human embryonic kidney cells (HEK 293 cells), stably expressing human mGluR5, were plated out in 384-well clear-bottomed plates (50 $\mu \mathrm{L}$ of cells, approx. 10,000 cells per well) in DMEM 1X medium (10\% FCS and $500 \mu \mathrm{g} / \mathrm{ml}$ Geneticin). Twenty-four hours later, the cells were washed with Hanks buffer (HBSS 10X (with $\mathrm{Ca}^{2+}, \mathrm{Mg}^{2+}$ ) and HEPES (1M), pH 7.4) and incubated with $20 \mu \mathrm{l}$ calcium sensitive fluorescence dye (FLIPR calcium 4 assay kit Molecular Devices, Sunnyvale, California), diluted in Hanks buffer, for 1 hour. In the NAM experiments, the cells were incubated with a range of concentrations of RO4917523 (10 $\mu \mathrm{M}-$ $30 \mathrm{pM})$ or MTEP $(10 \mu \mathrm{M}-30 \mathrm{pM})$, diluted in $1 \%$ DMSO, for 10 minutes. Intracellular calcium release measurements were made using a 384 fluorometric imaging plate reader (FLIPR) (FLIPR Tetra - Molecular Devices, Sunnyvale, California) in the presence of $30 \mu \mathrm{M}$ glutamate. In the PAM experiment, a glutamate dose-response shift experiment was performed with ADX47273, to demonstrate the allosteric properties of the compound. Following incubation with calcium sensitive fluorescence dye, the cells were incubated with a range of concentrations of ADX47273 (3 $\mu \mathrm{M}-10 \mathrm{nM})$, diluted in 1\% DMSO, for 10 minutes and then stimulated with a range of concentrations of glutamate $(0.3 \mathrm{mM}-1 \mathrm{nM})$.

\section{Results}

The effect of $30 \mu \mathrm{M}$ glutamate on intracellular calcium release is shown in Fig.S5a. RO4917523 and MTEP concentration-dependently attenuated this response with $\mathrm{IC}_{50}$ values of $4.53 \mathrm{nM}$ and $19.2 \mathrm{nM}$, respectively. Although these data do not confirm allosteric modulation, allosteric properties of the compounds can be assumed based on the structural properties of RO4917523 and MTEP and the structure of mGluR5 orthosteric versus allosteric binding sites (Doré et al., 2014; Jaeschke et al., 2015; Mølck et al., 2014). Nevertheless, these 
data demonstrate that both RO4917523 and MTEP have clear negative modulatory effects on mGluR5.

Application of glutamate to the cells produced a concentration-dependent increase in calcium release $\left(\mathrm{EC}_{50} 6.57 \mu \mathrm{M}\right)$ (Fig.S5b). The allosteric property of ADX47273 was demonstrated by the concentration-dependent leftward-shift of the glutamate-response curve (Fig. S5b). ADX47273 lowered the glutamate concentration threshold necessary for the cells to elicit a fluorescent response. In the presence of $3 \mu \mathrm{M}$ ADX47273 (highest concentration tested), the $\mathrm{EC}_{50}$ of glutamate was $0.31 \mu \mathrm{M}$ with a maximal shift factor of 21.2. ADX47273 had no intrinsic agonist activity at the maximal dose tested, evident by the absence of an upward shift in the dose-response function.

Fig. S5

(a)

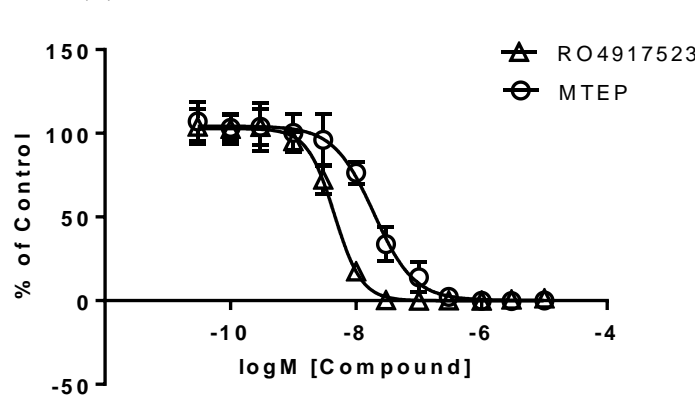

(b)

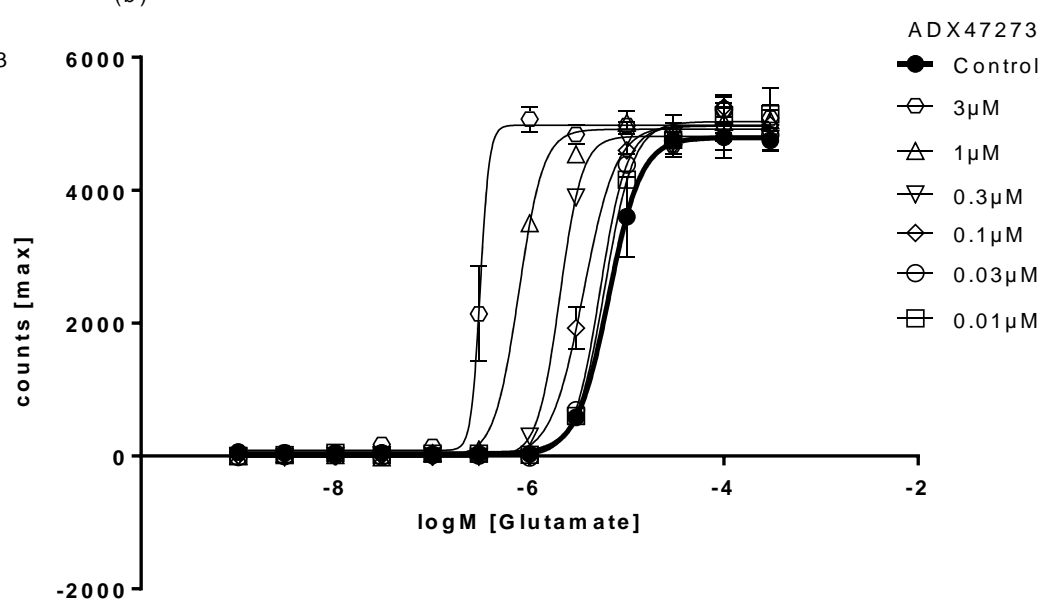

Fig. S5: (a) Attenuation of the effects of $30 \mu \mathrm{M}$ glutamate on mGluR5 activation by the negative allosteric modulators RO4917523 and MTEP. A range of concentrations of RO4917523 and MTEP were added to human mGluR5-expressing HEK 293 cells in the presence of $30 \mu \mathrm{M}$ glutamate. Concentration-response curves were generated from the mean data of a total of three experiments. (b) ADX47273 concentration-dependently lowered the glutamate concentration threshold necessary to activate mGluR5. The leftward-shift of the 
glutamate-response curve highlights the allosteric property of ADX47273. Data are means \pm SD.

\section{References}

Doré, A.S., Okrasa, K., Patel, J.C., Serrano-Vega, M., Bennett, K., Cooke, R.M., Errey, J.C., Jazayeri, A., Khan, S., Tehan, B., Weir, M., Wiggin, G.R., Marshall, F.H., 2014.

Structure of class C GPCR metabotropic glutamate receptor 5 transmembrane domain. Nature 511, 557-562. doi:10.1038/nature13396

Jaeschke, G., Kolczewski, S., Spooren, W., Vieira, E., Bitter-Stoll, N., Boissin, P., Borroni, E., Büttelmann, B., Ceccarelli, S., Clemann, N., David, B., Funk, C., Guba, W., Harrison, A., Hartung, T., Honer, M., Huwyler, J., Kuratli, M., Niederhauser, U., Pähler, A., Peters, J.-U., Petersen, A., Prinssen, E., Ricci, A., Rueher, D., Rueher, M., Schneider, M., Spurr, P., Stoll, T., Tännler, D., Wichmann, J., Porter, R.H., Wettstein, J.G., Lindemann, L., 2015. Metabotropic Glutamate Receptor 5 Negative Allosteric Modulators: Discovery of 2-Chloro-4-[1-(4-fluorophenyl)-2,5-dimethyl-1H-imidazol4-ylethynyl]-pyridine (Basimglurant, RO4917523), a Promising Novel Medicine for Psychiatric Diseases. J. Med. Chem. doi:10.1021/jm501642c

Mølck, C., Harpsøe, K., Gloriam, D.E., Mathiesen, J.M., Nielsen, S.M., Bräuner-Osborne, H., 2014. mGluR5: Exploration of Orthosteric and Allosteric Ligand Binding Pockets and Their Applications to Drug Discovery. Neurochem. Res. doi:10.1007/s11064-014$1248-8$ 